\title{
Co-infections and COVID-19 in Children: An Observational Study
}

\author{
1. Uzzal Kumar Ghosh \\ Registrar, Dept. of Paediatrics,
} Dr. M R Khan Shishu Hospital \& ICH, Mirpur-2, Dhaka.

\author{
2. MadhabiBaidya \\ AssistantProfessor, Dept. of Paediatric Gastroenterology \\ Hepatology and Nutrition, Dhaka Shishu (Children) \\ Hospital. \\ 4. Nobo Krishna Ghosh \\ Professor, Dept. of Paediatrics, Dr. M R Khan Shishu \\ Hospital \& ICH, Mirpur-2, Dhaka. \\ 6. Joairya Yasmeen Bushra \\ Assistant Registrar, Dept. of Paediatrics, Dr. M R Khan \\ Shishu Hospital \& ICH, Mirpur-2, Dhaka.
}

\author{
3. Azmeri Sultana \\ Associate Professor, Dept. of Paediatrics, Dr. M R Khan \\ Shishu Hospital \& ICH, \\ Mirpur-2, Dhaka. \\ 5. M. F. Abiduzzaman \\ Registrar, Dept. of Paediatrics, Dr. M R Khan Shishu \\ Hospital \& ICH, Mirpur-2, Dhaka. \\ 7. Md. Maniruzzaman Nayan \\ Trainee, Ibn Sina Medical College \& Hospital, \\ Kallaynpur, Dhaka.
}

COVID-191 (3.3\%), Atypical pneumonia with COVID$191(3.3 \%)$ were found. RT-PCR was positive forCOVID-1930(100\%), blood culture was positive for Salmonella Typhi $4(13.3 \%)$, Widal test was reactive (high rising titer) $\mathbf{8}(\mathbf{2 6 . 7 \%})$, Latex agglutination test was positive for bacterial meningitis $6(20 \%)$, urine culture was positive for E.coli $3(\mathbf{1 0 \%})$, blood culture was positive

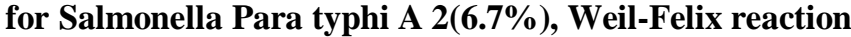
was found (high rising titer) $2(6.7 \%$ ), Anti HAV IgM was positive $2(6.7 \%)$, Anti HEV IgM was positive $\mathbf{1}(3.3 \%)$, Blood culturewas positive for Septic arthritis 1(3.3\%), blood culture was positive for Mycoplasma Pneumoniae 1(3.3\%).

\section{Conclusion:}

This study showed that COVID-19 in Bangladeshi children was found associated with co-infections. So, coinfection with COVID-19 patients should be closely monitored and managed accordingly.

Keywords:- Co-infections, COVID-19.

\section{INTRODUCTION}

Coronaviruses (CoVs) are an enveloped, singlestranded, zoonotic, RNA viruses oflarge family. The novel CoVs severe acute respiratory syndrome coronavirus (SARS-CoV) emerged in 2002. The 2019 novel coronavirus (SARS-CoV-2) is currently causing a severe outbreak of disease (called COVID-19) in China and multiple other countries including Bangladesh. Now it is a pandemic and global health concern. In humans, CoVs mostly cause respiratory and gastrointestinal symptoms. Clinical manifestations range from a common cold to severe disease such as bronchiolitis, pneumonia, ARDS, inflammatory syndrome, multi-organ failure and even death. SARS-CoV and SARS-CoV-2 less commonly affect children and less 
severe disease compared with adults, and are associated with lower fatality. Evidence suggests children are as likely as adults to become infected with SARS-CoV-2 but are less likely to be symptomatic. The majority of children infected by novel CoVs have a documented household contact. In contrast, adults more often have a nosocomial exposure. ${ }^{1}$

According toNational Guidelines on Clinical Management of Coronavirus Disease 2019 (COVID-19) in Bangladesh shows corona symptoms are Mild illness (Influenza like illness-ILI), Pneumonia, Severe pneumonia, Acute respiratory distress syndrome, Sepsis, Septic shock. ${ }^{2}$

Common symptoms of COVID-19 in children are cough and fever. It is important to note that these symptoms may not always be present; thus, a high index of suspicion for SARS-CoV-2 infection is required in children. ${ }^{3}$

China and United States reported only about $2.4 \%$ coronavirus infection among children where age was under 19 years. ${ }^{\mathbf{4}} \mathbf{5}$. Most cases in children are mild, and treatment consists of supportive care. No drugs or biologics have been approved by the US Food and Drug Administration (FDA) for the prevention or treatment of COVID-19, and no vaccine is currently available. ${ }^{6}$

UK study says majority of patients under 18 years old experienced a mild disease and less than $1 \%$ of them died. ${ }^{7}$

A study of European children with COVID-19 suggests deaths are extremely rare. Four of the 582 children studied died, two of whom had known underlying health conditions. Children's symptoms were generally mild. Some who tested positive had no symptoms, but about one in 10 in the study needed intensive care. ${ }^{\mathbf{8}}$

Nearly one-half of the infected children had coinfection with other common respiratory pathogens. ${ }^{9}$ Fourty patients $(83 \%)$ had significant preexisting co morbidities. ${ }^{\mathbf{1 0}}$

Acute illness is caused by bacteria, viruses and parasites. Co-infection is the simultaneous infection of a host by multiple pathogens. COVID-19 in children with other infections is rarely reported in our country. In this pandemic situation, children with recent illness may be associated with coronavirus infection. Recent illness is nonresponding to conventional \& appropriate treatment or detoriating or atypically present; when they are might be associated with coronavirus infection. COVID-19 symptoms may mimic with various other diseases. Febrile phase of dengue fever, typhoid fever, paratyphoid fever, typhusor rickettsial fever, malaria, and many other diseases may be overlaps with the coronavirus infection that lead to substantial misdiagnosis.

In this view, high index of suspicion, careful attention to clinical course and RT-PCR are necessary to identify the corona virus infection with recent illnesses. Delay in diagnosis of associated COVID-19 results bad prognosis. This study was performed to find out the corona virus infection associated with recent illnesses.

\section{METHODOLOGY}

An observational study was done at Dr. M R Khan Shishu Hospital \& ICH, Mirpur-2, Dhaka from April 2020 to June 2020. Patient with fever, rash, cough, respiratory distress, vomiting, diarrhea, dysuria, convulsion, jaundice and other symptoms; admitted in hospital were taken for this study. Diagnosis was made by clinical symptoms criteria plus investigations accordingly and appropriate treatment were given. During follow up these cases; we observed that those patients had persistence of high-grade non remitting fever, rash, vomiting, burking/dry cough, deepening of jaundice, uncontrolled convulsion\& some other new features appeared. These features could not be correlated with the specific disease symptoms in spite of getting appropriate treatment. These arouse our suspicion that there might be some associated with corona virus infection in this pandemic. Then nasopharyngeal and oropharyngeal swab were taken and sent for RT-PCR for COVID-19. Typhoid and paratyphoid feverwere diagnosed by either blood culture or very high titer of Widal test where T: O/A: Omore than 1:320 and rising titer subsequently. Typhus fever was identified by Weil-Felix reaction OX titer of 1:320 or an increasein OX titer in the follow-up. Bacterial meningitis was diagnosed by CSF studywith bacterial Antigen test (Latex agglutination test). Hepatitis A virus infection was diagnosed by rapid very high rise ofSGPT, prolonged PT, rising of serum bilirubin and Anti HAV IgM positive. Hepatitis $\mathrm{E}$ virus infection was identified by abnormal liver function test with Anti HEV IgM positive. Pneumonia causing organism isolated by blood culture. Septic arthritis was diagnosed by blood culture and X-ray of affected joint. Urinary tract infection by urine routine microscopic examination \& urine culture positive for organism with significant colony count.Co-infection with COVID-19 were our case experience $(\mathrm{N})$.

\section{RESULTS}

Thirty cases were taken co-infection withCOVID19.Here sample size $\mathrm{N}=30$

Age was found 4 months to 8 years.

Among the patients of co-infection withCOVID-19; male was $18(60 \%)$ and female was $12(40 \%)$. Male female ratio was 1.5: 1 (Table I)

\begin{tabular}{|c|c|c|}
\hline Gender & Number (n) & Percentage (\%) \\
\hline Male & 18 & 60 \\
\hline Female & 12 & 40 \\
\hline
\end{tabular}

Table I showing gender distribution of study sample $(\mathrm{N}=30)$

Among the patients of different infections with COVID-19; Typhoid fever with COVID-19was12(40\%), Bacterial meningitis with COVID-19 was 6(20\%), UTI with COVID-19 was3(10\%), Paratyphoid fever with COVID-19 was2(6.7\%), Typhus/Rickettsial fever with COVID-19 was2 $(6.7 \%)$, Acute viral hepatitis (HAV infection) with 
COVID-19 was2(6.7\%), Acute viral hepatitis (HEV infection) with COVID-19 was1 (3.3\%), Septic arthritis with
COVID-19 was1 (3.3\%), Atypical pneumonia withCOVID19 was1 $(3.3 \%)$. (Table II)

\begin{tabular}{|c|c|c|}
\hline Diagnosis & Number (n) & Percentage (\%) \\
\hline Typhoid fever with COVID-19 & 12 & 40 \\
\hline Bacterial meningitis with COVID-19 & 6 & 20 \\
\hline UTI with COVID-19 & 3 & 10 \\
\hline Paratyphoid fever with COVID-19 & 2 & 6.7 \\
\hline Typhus/Rickettsial fever with COVID-19 & 2 & 6.7 \\
\hline Acute viral hepatitis (HAV infection) with COVID-19 & 2 & 3.3 \\
\hline Acute viral hepatitis (HEV infection) with COVID-19 & 1 & 3.3 \\
\hline Septic arthritis with COVID-19 & 1 & \\
\hline Atypical pneumonia with COVID-19 & 1 & 3.3 \\
\hline
\end{tabular}

Table II:- showing different disease pattern with COVID-19 $(\mathrm{N}=30)$

RT-PCR was positive for COVID-1930(100\%), blood culture was positive for Salmonella Typhi 4(13.3\%),Widal test was reactive (high rising titer) $8(26.7 \%)$, Latex agglutination test was positive for Bacterial meningitis $6(20 \%)$, urine culture was positive for E.coli 3(10\%), blood culture was positive for Salmonella Paratyphi A
2(6.7\%),Weil-Felixreaction (high rising titer)was2(6.7\%), Anti HAV IgM was positive (hepatitis A virus infection)2(6.7\%), Anti HEV IgM was positive (hepatitis E virus infection) $1(3.3 \%)$, Blood culture was positive for Septic arthritis $1(3.3 \%)$, blood culture was positive for Mycoplasma Pneumoniae 1(3.3\%) (Table III)

\begin{tabular}{|c|c|c|}
\hline Attributes & Number (n) & Percentage (\%) \\
\hline COVID-19 & 30 & 100 \\
\hline RT-PCR positive & & 13.3 \\
\hline Enteric fever & 4 & 26.7 \\
\hline Blood C/S positive for S. typhi & 8 & 20 \\
\hline Widal test reactive & 6 & \\
\hline Bacterial Meningitis & & 10 \\
\hline Latex agglutination test positive & 3 & 6.7 \\
\hline Urinary tract infection & 2 & 6.7 \\
\hline Urine C/S positive for E. coli (more than $10^{5}$ ) & & \\
\hline Blood C/S positive for S. paratyphi A & 2 & 6.7 \\
\hline Typhus fever & & 3.3 \\
\hline Weil-Felix reaction & 2 & \\
\hline Acute viral hepatitis & 1 & 3.3 \\
\hline Anti HAV IgM positive & & \\
\hline Anti HEV IgM positive & 1 & 3.3 \\
\hline Septic Arthritis & & \\
\hline Blood C/S positive for Staph. aureus & 1 & \\
\hline Atypical pneumonia & & \\
\hline Blood C/S positive for Mycoplasma Pneumoniae & & \\
\hline
\end{tabular}

Table III showing pattern of investigation findings for diagnosis of different disease with COVID-19 (N=30)

\section{DISCUSSION}

In this study 30 cases of co-infection with COVID-19 were taken. Age was found 4 months to 8 years. Among the patients of co-infection with COVID-19; male was 18 and female was 12 .

Among the 30 patients of different infections with COVID-19; Typhoid fever with COVID-19 was 12 cases, Bacterial meningitis with COVID-19 was 6 cases, UTI with COVID-19 was 3 cases, Paratyphoid fever with COVID-19 was 2 cases, Typhus/Rickettsial fever with COVID-19 was 2 cases, Acute viral hepatitis (HAV infection) with COVID19 was 2 cases, Acute viral hepatitis (HEV infection) with
COVID-19 was one case, Septic arthritis with COVID-19 was one case, Atypical pneumonia with COVID-19 was one case.

All cases were RT-PCR positive for COVID-19. Blood culture was positive for Salmonella Typhi 4 cases, Widal test was reactive (high rising titer) 8 cases, Latex agglutination test was positive for Bacterial meningitis 6 cases, urine culture was positive for E.coli 3 cases, blood culture was positive for Salmonella Paratyphi A 2 cases, Weil-Felix reaction (high rising titer) was 2 cases, Anti HAV IgM was positive (hepatitis A virus infection 2 cases, Anti HEV IgM was positive (hepatitis E virus infection) one cases, blood culture was positive for Septic arthritis one 
case, blood culture was positive for Mycoplasma Pneumoniae one case.

In this study, Bangladeshi children were found typhoid fever with COVID-19 as a co-infection predominantly.COVID-19 and Salmonella Typhi coepidemics in Pakistan. Those articles have pointed the impact of co-epidemics/co-infections of COVID-19 and other infectious diseases on an already overburdened. Pakistan is entirely occupied with the COVID-19 catastrophe; simultaneously around 20000 typhoid cases within 10 days of June 2020 have also been reported along with COVID-19. ${ }^{11}$

Dengue and COVID-19 co-infection is a deadly combination. Still in Bangladesh dengue is a major public health problem. Every year many people including children die due to dengue fever with its complication. Althoughit was an important concern but in our study no case was identified of dengue fever with COVID-19. A case has been reported, co-infection of dengue and COVID-19; share common clinical and laboratory features. ${ }^{\mathbf{1 2}}$

Our study showed bacterial meningitis with COVID19 as a co-infection.A case report of nosocomial infection with SARS CoV-2 in a one-year old Meningoencephalitis patient in a tertiary hospital of Bangladesh. ${ }^{13}$

We found acute hepatitis with COVID-19 as a coinfection with hepatitis A or hepatitis $\mathrm{E}$ virus. A study was found where COVID-19 presenting as Acute Hepatitis. ${ }^{14}$

Pediatric patients with COVID-19 presented with distinct epidemiological, clinical, and radiologic characteristics from adult patients. Nearly one-half of the infected children had co-infection with other common respiratory pathogens. ${ }^{15}$

One case reported in our study was mycoplasma pneumoniae with coronavirus infection as a co-infection. In children, the co-infection rate was seen for adenovirus $\mathrm{C}$ and influenza B virus at $68.4 \%, 10.7 \%$ respectively. Significantly lower co-infection rates were seen for influenza viruses and human metapneumo virus compared with other viral strains. Rhinovirus was identified associated with the most co-infections overall and co-infection rate in children at $33.3 \%$, where adults was only $5 \% .^{16}$

A case reported, a 4-month-old boy with a muscular ventricular septal defect and atopic dermatitis presentedwith gastroenteritis and respiratory tract infection with documented history of home exposure to COVID-19. The initial respiratory pathogen was positive for adenovirus. But infollowing day, the COVID-19 PCR was also positive. ${ }^{17}$

Bangladesh is a small developing country.Population is gradually increasing and theylive in overcrowded places. Sanitation system, water supply system, disinfection system is still in developing. So communicable diseases, infectious diseases, waterborne diseases, mosquito borne diseases are common.But successful EPI vaccination program in
Bangladesh reduces communicable and infectious diseasesassociated morbidity and mortality.

\section{LIMITATION}

Severity and outcome of co-infections with COVID-19 could not have mentioned in our study. Virus isolation could not be possible in our settings. So, co-infection by other viruses along with coronavirus missed to identify.

\section{CONCLUSION}

This study showed thatCOVID-19 inBangladeshi children were found associated with co-infections. So, coinfection with COVID-19patients should be closely monitored and managed accordingly. Here, we have to mention that childhood disease pattern depends on different epidemiological and geographical location. So, co-infection pattern with COVID-19 can varies. But our study concluded that co-infection is not very uncommon with COVID-19.

\section{RECOMMENDATION}

Co-morbidities is a great concern with COVID-19. So, co-infection with COVID-19 might be a concern also. Epidemiological and geographical basis study is recommended.

\section{Conflict of interest}

No conflict of interest.

\section{ACKNOWLEDGEMENT}

Grateful to all the Authors of Dr. M R Khan Shishu hospital \& Institute of Child Health, and Dhaka Shishu (Children) Hospital.

\section{REFERENCES}

[1]. Zimmermann, Petra, Curtis, Nigel. Coronavirus Infections in Children Including COVID-19. The Pediatric Infectious Disease Journal, May 2020; 39(5): 355-368. doi:10.1097/INF.0000000000002660.

[2]. National Guidelines on Clinical Management of Coronavirus Disease 2019 (COVID-19); Version 4.0 30 March 2020: Disease Control Division, Directorate General of Health Services, Ministry of Health \& Family Welfare, Government of the People's Republic of Bangladesh. Page 9-10.

[3]. Issa B, Cennimo DJ. Coronavirus Disease 2019 (COVID-19) in Children. Medscape. Drugs \& Diseases>Pediatrics: General Medicine; updated Jul 23, 2020.

[4]. WHO. Report of the WHO-China Joint Mission on Coronavirus Disease 2019 (COVID-19). World Health Organization. 2020 Feb 28; Accessed: April 9, 2020.

[5]. CDC COVID-19 Response Team. Coronavirus Disease in Children- United States, February 12-April 2, 2020; 69 (14):422-6. 
[6]. NIH Clinical Trial Shows Remdesivir Accelerates Recovery from advanced COVID-19. National Institute of Allergy and Infectious Diseases (NIAID).2020 Apr 29.

[7]. Dr. Ayodola Adigun. COVID-19 disease in children is usually mild, fatalities rare, Abc News Coronavirus Health \& Science 26 June 2020.

[8]. Coronavirus: Most children 'experience only mild disease'. Health: BBC News 26 June 2020.

[9]. Wu Q, Xing Y, Shi L, Li W. Co-infection and Other Clinical Characteristics of COVID-19 in Children. Pediatrics May 2020; 146(1):e20200961. DOI: 10.1542/peds.2020-0961.

[10]. Shekerdemian LS, Mahmood NR, Wolfe KK, Riggs BJ, Ross CE, Christine AC et al. Characteristics and Outcomes of Children with Coronavirus Disease 2019 (COVID-19) Infection Admitted to US and Canadian Pediatric Intensive Care Units. JAMA Pediatr. May 11, 2020.doi:10.1001/jamapediatrics.2020.1948.

[11]. Haqqi A, Khurram M, Salah Ud Din M, Aftab MN, Ali M, Ahmed H, Afzal MS. COVID-19 and Salmonella Typhi co-epidemics in Pakistan: A real problem 10 Jul 2020. doi: 10.1002/jmv.26293.

[12]. Verduyn M, Allou N, Gazaille V, Andre M, Desroche T, Jaffar M-C, et al. (2020) Co-infection of dengue and COVID-19: A case report. PLoSNegl Trop Dis 14(8): e0008476. https://doi.org/10.1371/journal.pntd.0008476.

[13]. Akram A, Jewel MSH, Chowdhury R, Chowdhury MRU. A case report of nosocomial infection with SARS CoV-2 in a one-year old Meningoencephalitis patient in a tertiary hospital of Bangladesh. Microbes and Infectious Diseases, 2020.

[14]. Wander P, Epstein M, Bernstein D. COVID-19 Presenting as Acute Hepatitis. The American Journal of Gastroenterology 1 April 2020; 115(6): DOI: 10.14309/ajg.0000000000000660.

[15]. Wu Q, Xing Y, Shi L, Li W, Gao Y, Pan S, Wang Y, Wang W, Xing Q. Co-infection and Other Clinical Characteristics of COVID-19 in Children. Pediatrics July 2020, $146 \quad$ (1) e20200961; DOI: https://doi.org/10.1542/peds.2020-0961.

[16]. Mandelia Y, Procop GW, Richter SS, Worley S, Liu W, Esper F. Dynamics and predisposition of respiratory viral co-infections in children and adults [published online June 12, 2020]. Clin Microbiol Infect.doi: 10.1016/j.cmi.2020.05.042.

[17]. Danley K, Kent P. 4-month-old boy coinfected with COVID-19 and adenovirus.Unusual association of diseases/symptoms Case report 2020; 13(6): http://orcid.org/0000-0003-0726-6349. 